\title{
Burden of hospitalizations and outpatient visits associated with moderate and severe acute graft-versus-host disease in Finland and Sweden: a real-world data study
}

\author{
Lorenzo Sabatelli $^{1} \mathbb{0} \cdot$ Mikko Keränen $^{2} \cdot$ Elisabet Viayna $^{3} \cdot$ Montserrat Roset $^{3} \cdot$ Nuria Lara $^{3} \cdot$ Daniel Thunström $^{1}$. \\ Minja Pfeiffer ${ }^{1} \cdot$ Malin Nicklasson $^{4} \cdot$ Maija Itälä-Remes $^{5}$
}

Received: 31 August 2021 / Accepted: 12 February 2022 / Published online: 2 March 2022

(c) The Author(s) 2022

\begin{abstract}
Purpose The aim of this study was to describe patient characteristics and quantify hospital stays and outpatient visits (H\&OV) following diagnosis with moderate-to-severe acute graft-versus-host disease (aGVHD) in Finland and Sweden. Methods A retrospective chart audit collected data from patient medical records of 3 specialized centers performing allogeneic hematopoietic stem cell transplantation (HSCT; Finland, $n=2$; Sweden, $n=1$ ). Eligible patients received allogeneic HSCT (January 1, 2016-June 30, 2017) from any donor source, were diagnosed with grade II-IV aGVHD (MAGIC or modified Glucksberg criteria) at any time from transplantation to 12 months before data collection, and were $\geq 18$ years old at diagnosis. Criteria for comparing patients graded with modified Glucksberg and MAGIC severity scales were defined.

Results Fifty-five patients (Finland, $n=45$; Sweden, $n=10$ ) were included. Myeloablative conditioning was the most common conditioning regimen (81.8\%); immunosuppression regimens were based on combinations of methotrexate (96.4\%), in vivo T-cell depletion (80.0\%), cyclosporine (63.6\%), mycophenolate (40.0\%), and tacrolimus (34.5\%). Sixteen patients (29.1\%) developed grade III/IV aGVHD; skin was the most common organ involved (80.0\%). Most patients required $\geq 1$ hospital stay (89.1\%; median of 2 hospitalizations per patient); 7 patients (14.3\%) required admission to an intensive care unit. Median hospitalization duration from HSCT to discharge was 26 days. Most patients also required outpatient or emergency department visits (90.9\%). Subgroup analyses showed longer hospital stays for patients receiving multiple treatment lines; no clear differences in $\mathrm{H} \& \mathrm{OV}$ were observed between prophylactic regimens.

Conclusion Based on this retrospective study, moderate-to-severe aGVHD is associated with considerable healthcare resource utilization in Finland and Sweden, particularly in patients who received multiple lines of therapy.
\end{abstract}

Keywords Acute graft-versus-host disease $\cdot$ Outpatient $\cdot$ Hospitalization $\cdot$ Real-world data $\cdot$ Severity grades $\cdot$ MAGIC $\cdot$ Glucksberg

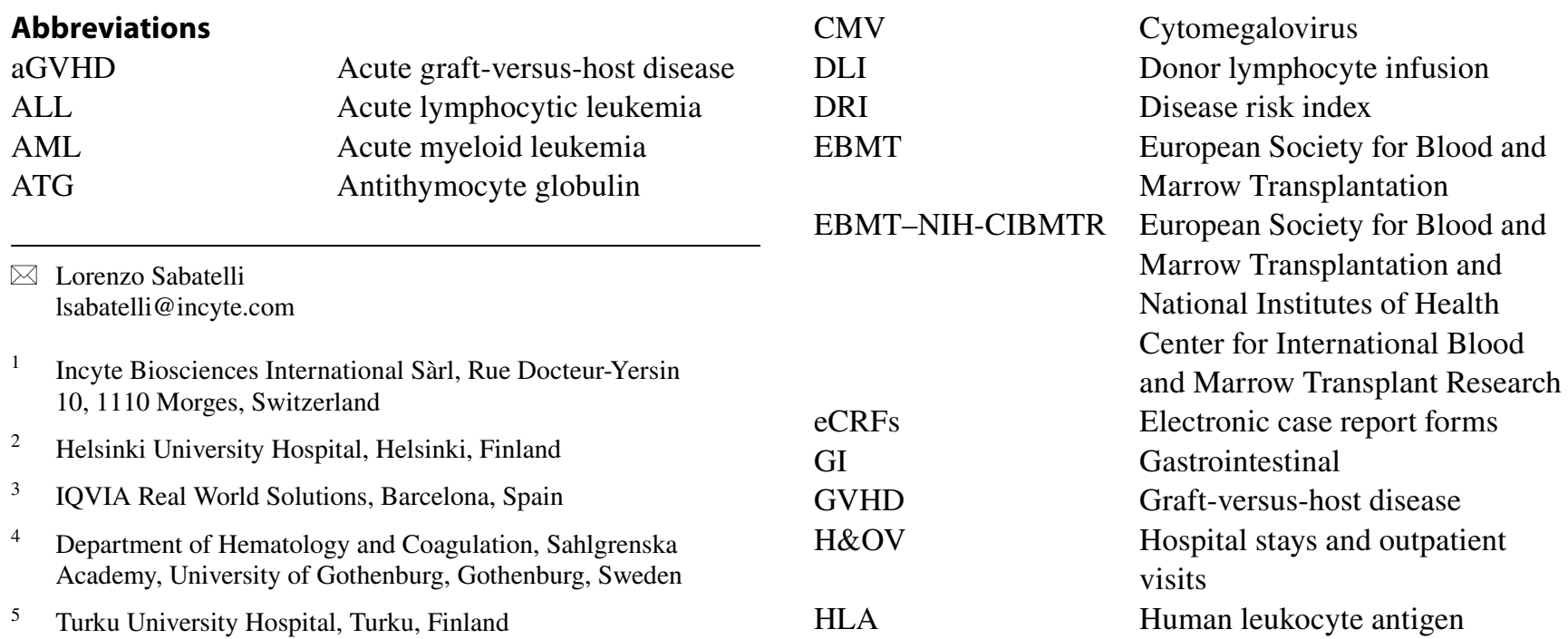




$\begin{array}{ll}\text { HSCT } & \begin{array}{l}\text { Hematopoietic stem cell } \\ \text { transplantation } \\ \text { International Blood and Marrow } \\ \text { Transplant Research }\end{array} \\ \text { IBMTR } & \begin{array}{l}\text { Intensive care unit } \\ \text { Myeloablative conditioning } \\ \text { ICU }\end{array} \\ \text { MAC } & \begin{array}{l}\text { Mount Sinai Acute GVHD Inter- } \\ \text { national Consortium }\end{array} \\ \text { MAGIC } & \text { Myelodysplastic syndrome } \\ \text { MDS } & \text { Myeloproliferative neoplasm } \\ \text { MPN } & \text { Non-Hodgkin lymphoma } \\ \text { NHL } & \text { Peripheral blood stem cell } \\ \text { PBSC } & \text { Progressive disease } \\ \text { PD } & \text { Reduced intensity conditioning } \\ \text { RIC } & \text { Real-world data } \\ \text { RWD } & \text { Total body irradiation } \\ \text { TBI } & \text { US dollars } \\ \text { USD } & \end{array}$

\section{Introduction}

Graft-versus-host disease (GVHD), a serious complication of allogeneic hematopoietic stem cell transplantation (HSCT), is a clinical syndrome caused by the response of alloreactive donor $\mathrm{T}$ cells to histocompatibility antigens expressed on tissues of the transplant recipient $[1,2]$. The European Society for Blood and Marrow Transplantation and National Institutes of Health Center for International Blood and Marrow Transplant Research (EBMT-NIH-CIBMTR) joint classification for acute GVHD (aGVHD) includes classic aGVHD, defined by the occurrence of aGVHD manifestations within 100 days after transplantation or donor lymphocyte infusion (DLI), as well as persistent, recurrent, or late-onset forms of aGVHD, which occur beyond 100 days posttransplantation or after DLI [3, 4]. Clinical manifestations of aGVHD typically develop in the skin, gastrointestinal (GI) tract, or liver, leading to erythema, maculopapular rash, nausea, vomiting, anorexia, diarrhea, ileus, increase of liver transaminases, or cholestatic hyperbilirubinemia; severity of aGVHD is determined by the extent of involvement of these principal target organs $[2,4,5]$.

Despite routine use of prophylactic regimens, aGVHD occurs in 30 to $60 \%$ of patients undergoing allogeneic HSCT $[6,7]$. Corticosteroids are currently a standard of care for first-line therapy for aGVHD. However, up to $60 \%$ of patients do not respond adequately to steroids [8-11]. For these patients, a choice of second-line therapy remains controversial.

Acute GVHD is a leading cause of post-HSCT nonrelapse mortality and has been previously associated with increased hospital stays and outpatient visits (H\&OV). However, realworld data (RWD) for aGVHD-related outcomes of transplanted patients and the associated $\mathrm{H} \& \mathrm{OV}$ are scarce and partly outdated. A retrospective analysis of patients undergoing allogeneic HSCT between 2006 and 2009 in the UK showed significantly higher rates of hospital readmission leading to higher costs for patients with GVHD compared to those without [12]. Furthermore, retrospective analyses from large US hospitals have shown that patients who developed aGVHD, especially in the subgroups of steroid-refractory or high-risk disease, had significantly longer hospital stays, higher rates of hospital readmissions, higher intensive care unit (ICU) admission rates, greater costs, and increased risk of mortality compared with those who did not develop GVHD [13-15].

Currently, there are only a few studies reporting aGVHDrelated morbidity and mortality or H\&OV-related healthcare resource utilization in contemporary European transplantation centers [16, 17]; thus, RWD analyses from additional sample populations in European countries are needed to more precisely determine GVHD-related burden. The aim of this study was to describe the clinical presentation, prophylactic treatments, hospitalizations, and outpatient visits among patients who developed moderate or severe aGVHD.

\section{Methods}

\section{Study design and patients}

This was a noninterventional, retrospective chart review study that originally planned to enroll patients in 4 European countries (Germany, Italy, Sweden, and Finland); however, due to the sponsor's decision to reduce the scope of the study for resource considerations, study data were ultimately retrieved from 2 sites in Finland (Turku and Helsinki) and one site in Sweden (Gothenburg). The sites were specialized centers belonging to the EBMT that routinely perform allogeneic HSCT. Patients were included retrospectively and consecutively, starting with those who received HSCT on June 30, 2017, and subsequently developed aGVHD, and working backward recruiting those who had received HSCT until January 1, 2016, or until the target sample size of approximately 4 to 25 patients per center had been reached, whichever occurred first (Online Resource 1). Patient charts were reviewed from the index date (date of allogeneic HSCT) until the day of data collection, death, or loss to follow-up, whichever occurred first.

Study eligibility criteria included receipt of a first allogeneic HSCT between January 1, 2016, and June 30, 2017, from any donor source using bone marrow, peripheral blood stem cells (PBSCs), or umbilical cord blood; diagnosis of grade II-IV aGVHD based on Mount Sinai Acute GVHD International Consortium (MAGIC) criteria [18] (or alternatively, a II-IV severity grade per the Glucksberg Severity Index or the Keystone Criteria [19], or grade B-D according 
to International Blood and Marrow Transplant Research (IBMTR) criteria [20]) any time from transplantation to 12 months before data collection; and age $\geq 18$ years at the time of aGVHD diagnosis. Only patients with complete clinical records containing the main clinical characteristics related to the original disease requiring allogeneic HSCT and clinical information on aGVHD presentation and treatment were included. Exclusion criteria included receipt of $>1$ HSCT; participation in a GVHD prophylaxis trial with a primary completion date later than December 31, 2018 (to ensure that trial results would be available by the time of patient enrollment), or in any GVHD treatment trial at any point during the data collection period (i.e., January 2016 until the time of data collection, death, or loss to followup); disease progression before the first aGVHD episode; or aGVHD following DLI.

\section{Data collection}

Patient data were collected from patient medical records and entered into electronic case report forms (eCRFs). Data from the eCRFs corresponding to eligibility criteria were regularly reviewed to ensure inclusion of eligible patients only and for consistency. Data on patient demographics, transplant characteristics, disease risk index (DRI; an index for stratification of patients undergoing HSCT by disease risk) [21, 22], aGVHD clinical characteristics, treatments, outcomes, and H\&OV (hospitalizations/inpatient admissions and outpatient and emergency department visits) were collected. For each patient, length of hospitalizations and ICU stays were calculated based on date of admission and discharge; only hospitalizations and ICU stays that took place during or after aGVHD diagnosis were considered. If a patient was in the hospital at the time of aGVHD diagnosis, the ongoing hospitalization episode was included in the analysis, but any days spent in the hospital before the diagnosis were not considered.

Transplant conditioning regimens were recorded and classified as myeloablative conditioning (MAC), reducedintensity conditioning (RIC), and sequential conditioning. Prophylactic regimen categories included ex vivo T-cell depletion, in vivo T-cell depletion (antithymocyte globulin [ATG], alemtuzumab, other), cyclosporine, steroid, tacrolimus, posttransplant cyclophosphamide, methotrexate, mycophenolate, sirolimus, and other. Data were collected on the number of treatment lines initiated.

\section{Statistical analyses}

All disease diagnoses (e.g., comorbidities) and medical procedure terms were recorded and coded using the Medical Dictionary for Regulatory Activities. All computations were performed using SAS ${ }^{\circledR}$ version 9.2 or higher (SAS Institute,
Cary, NC, USA). To ensure comparability across different grading systems, aGVHD severity was compared across scales and based on extent of skin, liver, and GI involvement, with grades II-IV (MAGIC and modified Glucksberg/Keystone criteria) defined as skin stage $\geq 3$ and/or liver $\geq 1$ and/ or GI $\geq 1$, and grades B-D (IBMTR criteria) defined as skin stage $\geq 2$ and/or liver $\geq 1$ and/or GI $\geq 1$ (Online Resources $2 \mathrm{~A}$ and $\mathrm{B}$ ) [4]. Mapping rules to compare patients graded per MAGIC criteria with those graded using a different scale were derived from grade and organ score definitions specific to each scale (Online Resources 3 and 4).

Data were summarized using descriptive statistics. Continuous variables were reported using mean, median, standard deviation, interquartile range, minimum, and maximum. Categorical values were summarized as number and proportion of the total study population and by subgroups, where appropriate. Missing values were reported for categorical and continuous values but were excluded to calculate percentages of patients. Although the study has a descriptive design, the probability that subgroup differences in outcomes (large or larger than observed) could have occurred under the null hypothesis of no difference was calculated using $P$-values, if $\geq 10$ patients per category were reached. No $P$-value threshold was prespecified or used to draw conclusions. The chi-squared test was used to compare categorical variables, and the nonparametric Kruskal-Wallis test was used to compare continuous variables.

Subgroup analyses were conducted to evaluate differences in $\mathrm{H} \& \mathrm{OV}$ (e.g., number and length of hospitalizations, reasons for hospitalizations, number and length of ICU admissions, number of and reasons for emergency department and outpatient visits) based on number of treatment lines (1 vs $\geq 2$ lines of treatment) and type of prophylactic regimens received ( 1 tacrolimus plus mycophenolate, in vivo T-cell depletion and methotrexate; 2 in vivo T-cell depletion plus methotrexate and cyclosporine; 3 methotrexate plus cyclosporine; or 4 other). A change in treatment lines was defined as replacement of an anti-aGVHD drug with another antiaGVHD drug and/or addition of an anti-aGVHD drug to the previous regimen.

\section{Results}

\section{Patient characteristics}

Overall, there were approximately 50 patients in Finland and 80 patients in Sweden who developed grade II to IV aGVHD after HSCT from January 1, 2016, to June 30, 2017 (calculation based on EBMT data [23]). A total of 55 patients (Finland, $n=45$; Sweden, $n=10$ ) were treated in participating centers, met inclusion criteria, and were therefore included in this study (Table 1). Acute myeloid leukemia 
Table 1 Patient demographics and clinical characteristics at transplant

\begin{tabular}{|c|c|c|c|}
\hline Characteristic & Finland $(n=45)$ & Sweden $(n=10)$ & Total $(N=55)$ \\
\hline \multicolumn{4}{|l|}{ Age at HSCT, $y$} \\
\hline Median (range) & $54.0(21.0-66.0)$ & $44.5(20.0-71.0)$ & $51.0(20.0-71.0)$ \\
\hline \multicolumn{4}{|l|}{ Age at aGVHD diagnosis, $y$} \\
\hline Median (range) & $54.0(21.0-66.0)$ & $44.5(20.0-71.0)$ & $51.0(20.0-71.0)$ \\
\hline Male, $n(\%)$ & $25(55.6)$ & $5(50.0)$ & $30(54.5)$ \\
\hline \multicolumn{4}{|l|}{ Primary disease diagnosis, $n(\%)$} \\
\hline AML & $16(35.6)$ & $3(30.0)$ & $19(34.5)$ \\
\hline Multiple myeloma & $8(17.8)$ & 0 & $8(14.5)$ \\
\hline B-cell lymphoma (NHL) & $3(6.7)$ & $2(20.0)$ & $5(9.1)$ \\
\hline MDS & $4(8.9)$ & 0 & $4(7.3)$ \\
\hline MPN & $4(8.9)$ & $1(10.0)$ & $5(9.1)$ \\
\hline ALL & $3(6.7)$ & $1(10.0)$ & $4(7.3)$ \\
\hline Hodgkin lymphoma & $3(6.7)$ & $1(10.0)$ & $4(7.3)$ \\
\hline Other $^{\mathrm{a}}$ & $3(6.7)$ & $2(20.0)$ & $5(9.1)$ \\
\hline \multicolumn{4}{|l|}{ Stage at transplant, $n(\%)$} \\
\hline Complete remission & $29(64.4)$ & $5(50.0)$ & $34(61.8)$ \\
\hline Partial remission & $9(20.0)$ & $3(30.0)$ & $12(21.8)$ \\
\hline Active relapse or PD & $5(11.1)$ & $1(10.0)$ & $6(10.9)$ \\
\hline Untreated & $2(4.4)$ & $1(10.0)$ & $3(5.5)$ \\
\hline \multicolumn{4}{|l|}{ DRI, ${ }^{\mathrm{b}} n(\%)$} \\
\hline Low & $8(17.8)$ & $2(20.0)$ & $10(18.2)$ \\
\hline Intermediate & $21(46.7)$ & $6(60.0)$ & $27(49.1)$ \\
\hline High & $9(20.0)$ & $2(20.0)$ & $11(20.0)$ \\
\hline Very high & $1(2.2)$ & 0 & $1(1.8)$ \\
\hline Unknown & $6(13.3)$ & 0 & $6(10.9)$ \\
\hline \multicolumn{4}{|l|}{ Stem cell source, $n(\%)$} \\
\hline PBSC & $45(100.0)$ & $8(80.0)$ & $53(96.4)$ \\
\hline Bone marrow & 0 & $2(20.0)$ & $2(3.6)$ \\
\hline Related donor, $n(\%)$ & $8(17.8)$ & $5(50.0)$ & $13(23.6)$ \\
\hline Fully HLA-matched twin & $5(62.5)$ & 0 & $5(38.5)$ \\
\hline HLA-mismatched related donor & 0 & $1(20.0)$ & $1(7.7)$ \\
\hline HLA-matched related donor & $3(37.5)$ & $4(80.0)$ & $7(53.8)$ \\
\hline Unrelated donor, $n(\%)$ & $37(82.2)$ & $5(50.0)$ & $42(76.4)$ \\
\hline HLA matched & 35 (94.6) & $5(100.0)$ & $40(95.2)$ \\
\hline HLA mismatched & $2(5.4)$ & 0 & $2(4.8)$ \\
\hline Recipient serologic CMV-positive status, $n(\%)$ & $29(64.4)$ & $8(80.0)$ & $37(67.3)$ \\
\hline \multicolumn{4}{|l|}{ Maximum level of chimerism, $n(\%)$} \\
\hline Full donor chimerism & $26(57.8)$ & $10(100.0)$ & $36(65.5)$ \\
\hline Mixed or partial chimerism after reaching full chimerism ${ }^{c}$ & $5(19.2)$ & $7(70.0)$ & $12(33.3)$ \\
\hline Unknown & $19(42.2)$ & 0 & $19(34.5)$ \\
\hline \multicolumn{4}{|l|}{ aGVHD organ symptom involvement, $n(\%)$} \\
\hline Skin & $37(82.2)$ & $7(70.0)$ & $44(80.0)$ \\
\hline Lower GI tract & $23(51.1)$ & $4(40.0)$ & $27(49.1)$ \\
\hline Liver & $11(24.4)$ & $1(10.0)$ & $12(21.8)$ \\
\hline Upper GI tract & $10(22.2)$ & 0 & $10(18.2)$ \\
\hline
\end{tabular}

$a G V H D$, acute graft-versus-host disease; $A L L$, acute lymphocytic leukemia; $A M L$, acute myeloid leukemia; $C M V$, cytomegalovirus; $D R I$, disease risk index; GI, gastrointestinal; HSCT, hematopoietic stem cell transplantation; HLA, human leukocyte antigen; MDS, myelodysplastic syndrome; $M P N$, myeloproliferative neoplasm; $N H L$, non-Hodgkin lymphoma; $P B S C$, peripheral blood stem cell; $P D$, progressive disease. ${ }^{\text {a }}$ "Other" includes chronic myeloid leukemia $(n=2)$, blastic plasmacytoid dendritic cell neoplasia, chronic myelomonocytic leukemia, and T-cell lymphoma ( $n=1$ each). ${ }^{b}$ DRI determined as described in Armand P, et al. Blood. 2014;123(23):3664-3671. ${ }^{\mathrm{c} A m o n g}$ patients who reached full chimerism (Finland, $n=26$; Sweden, $n=10$; total, $n=36$ ) 
was the most common indication for HSCT ( $n=19$ [34.5\%]), followed by multiple myeloma $(n=8[14.5 \%])$. At the time of HSCT, most patients were in complete ( $n=34$ [61.8\%]) or partial ( $n=12[21.8 \%])$ remission, and the most common DRI was intermediate $(n=27$ [49.1\%]). Most donors were unrelated $(n=42[76.4 \%])$, and of these, only 2 patients (4.8\%) received a human leukocyte antigen-mismatched graft. Most patients received a PBSC graft $(n=53$ [96.4\%]). All patients for whom chimerism was determined $(n=36)$ reached full donor chimerism as their maximum level of chimerism.

\section{Transplant conditioning regimen and aGVHD prophylaxis}

Myeloablative conditioning was the most common transplant conditioning regimen and was used in 45 transplants (81.8\%), followed by RIC in 9 transplants (16.4\%; Fig. 1A).
Fig. 1 Transplant conditioning regimen and aGVHD prophylaxis. A Type of conditioning regimen used, by country and overall. B Specific conditioning regimens by category (MAC or RIC). C aGVHD prophylaxis used by country. aGVHD, acute graft-versus-host disease; MAC, myeloablative conditioning; RIC, reduced-intensity conditioning; TBI, total body irradiation

\section{A}
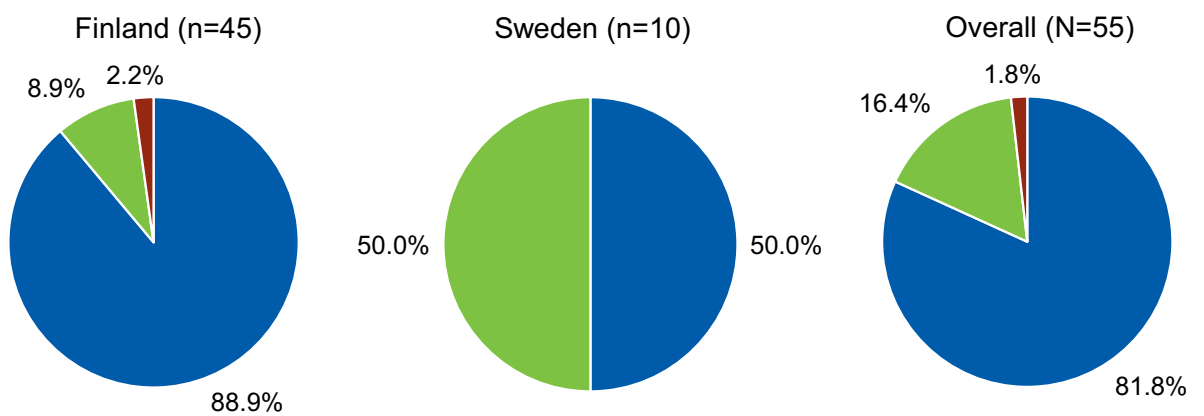

- Myeloablative $n$ Reduced intensity $\|$ Sequential

B

Type of Conditioning Regimen Used, \%

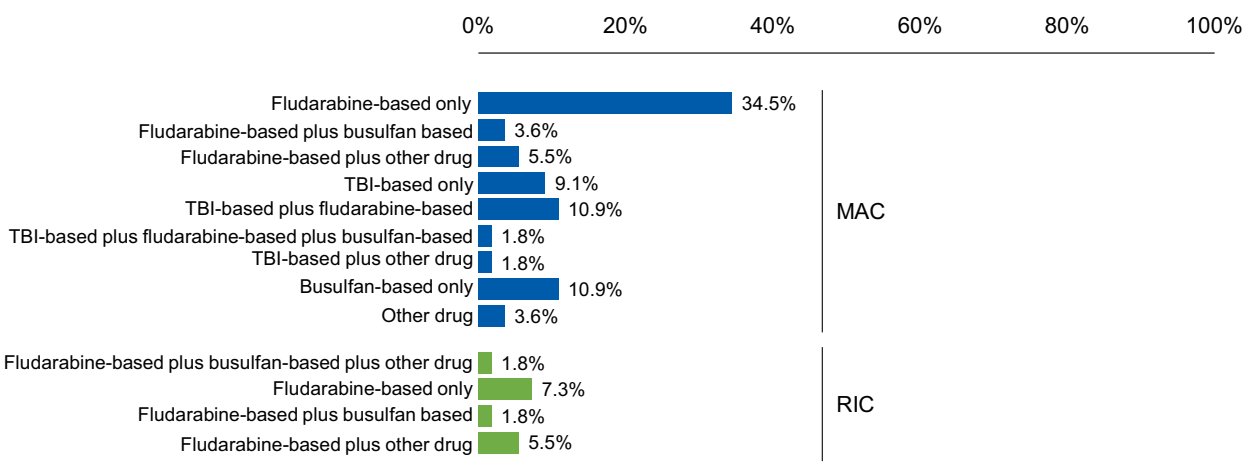

C

Type of Acute GVHD Prophylaxis Used, \%

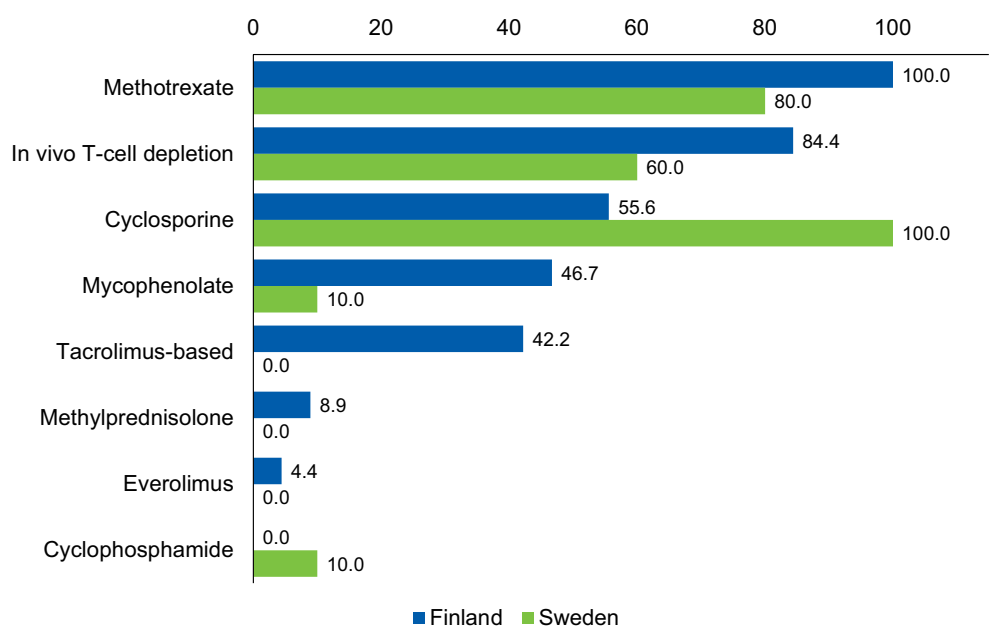


Most patients received fludarabine-based conditioning $(n=41 / 55$ [74.5\%]), and $15(27.3 \%)$ patients received total body irradiation (TBI)-based conditioning (Fig. 1B). Fludarabine was most frequently administered alone $(n=26 / 41 ; 63.4 \%)$, followed by combinations with TBI $(n=8 / 41$ [19.5\%]), thiotepa ( $n=4 / 41$ [thiotepa alone, $n=1$; thiotepa plus cyclophosphamide, $n=3$ ]; 9.8\%), treosulfan $(n=2 / 41$ [4.9\%]), or melphalan ( $n=1 / 41$ [2.4\%]). Busulfan administered over 3 or 4 days was defined as MAC, and over 2 days as RIC (the total of daily doses was the same). Treosulfan was administered over 3 days; a daily dose of $14 \mathrm{~g} / \mathrm{m}^{2}$ was classified as MAC, and a daily dose of $10 \mathrm{~g} / \mathrm{m}^{2}$ as RIC.

Immunosuppression was mainly based on the calcineurin inhibitors cyclosporine $(n=35 / 55$ [63.6\%]) and tacrolimus $(n=19 / 55$ [34.5\%]). Short-course methotrexate was used in almost all transplants ( $n=53 / 55$ [96.4\%]), and a majority of patients also received ATG as in vivo T-cell depletion $(n=44 / 55[80.0 \%])$. Mycophenolate mofetil was frequently added to the combination ( $n=22 / 55$ [40.0\%]; Fig. 1C).

The most frequent prophylaxis combination was cyclosporine, methotrexate, and ATG $(n=20 / 55$ [36.4\%]), followed by tacrolimus, methotrexate, ATG, and mycophenolate $(n=14 / 55[25.5 \%])$ and cyclosporine with methotrexate $(n=7 / 55[12.7 \%])$.

\section{Acute GVHD severity and organ symptom involvement}

The scales used for grading aGVHD severity across the 3 participating centers were MAGIC $(n=29 / 55$ [52.7\%]) or modified Glucksberg $(n=26 / 55$ [47.3\%]; Online Resource
5). Thirty-nine patients (70.9\%) and 16 patients (29.1\%) developed grade II and grades III/IV aGVHD, respectively. Skin was the most common organ involved $(n=44 / 55$ [80.0\%]), followed by the lower GI tract $(n=27 / 55$ [49.1\%]), liver $(n=12 / 55$ [21.8\%]), and upper GI tract $(n=10 / 55$ [18.2\%]; Table 1).

\section{Nonpharmacologic H\&OV since aGVHD diagnosis}

Most patients with aGVHD $(n=49 / 55$ [89.1\%]) required at least one hospitalization period, primarily due to aGVHD $(n=32 / 49$ [65.3\%]) or infections/infestations $(n=22 / 49$ [44.9\%]; Fig. 2). Median (range) number of hospitalization periods per patient was $2.0(0.0-10.0)$. Seven patients $(n=7 / 49$ [14.3\%]) required admission to an ICU (Fig. 2). From the date of HSCT to discharge during the initial transplant period, the median duration of hospitalization was 26.0 days (Table 2), and nearly half of all hospitalizations lasted $>7$ days ( $n=72 / 158$ [45.6\%]; Online Resource 6). Mean (SD) days spent in the hospital and ICU following aGVHD grade II-IV diagnosis per 100 days of observation were 17.9 (31.4) and 0.7 (2.7), respectively (Table 2). In addition, most patients required an outpatient or emergency department visit following aGVHD grade II-IV diagnosis ( $n=50 / 55$ [90.9\%]; Fig. 2). On average, patients required a mean (SD) 11.7 (11.1) outpatient and 0.3 (0.6) emergency visits per year (Table 2).
Fig. 2 H\&OV: hospitalizations and outpatient and emergency department visits. ${ }^{a}$ Percentages were calculated over the number of hospitalized patients and not over the whole study sample. aGVHD, acute graft-versus-host disease; GI, gastrointestinal; $\mathrm{H} \& \mathrm{OV}$, hospital stays and outpatient visits; ICU, intensive care unit

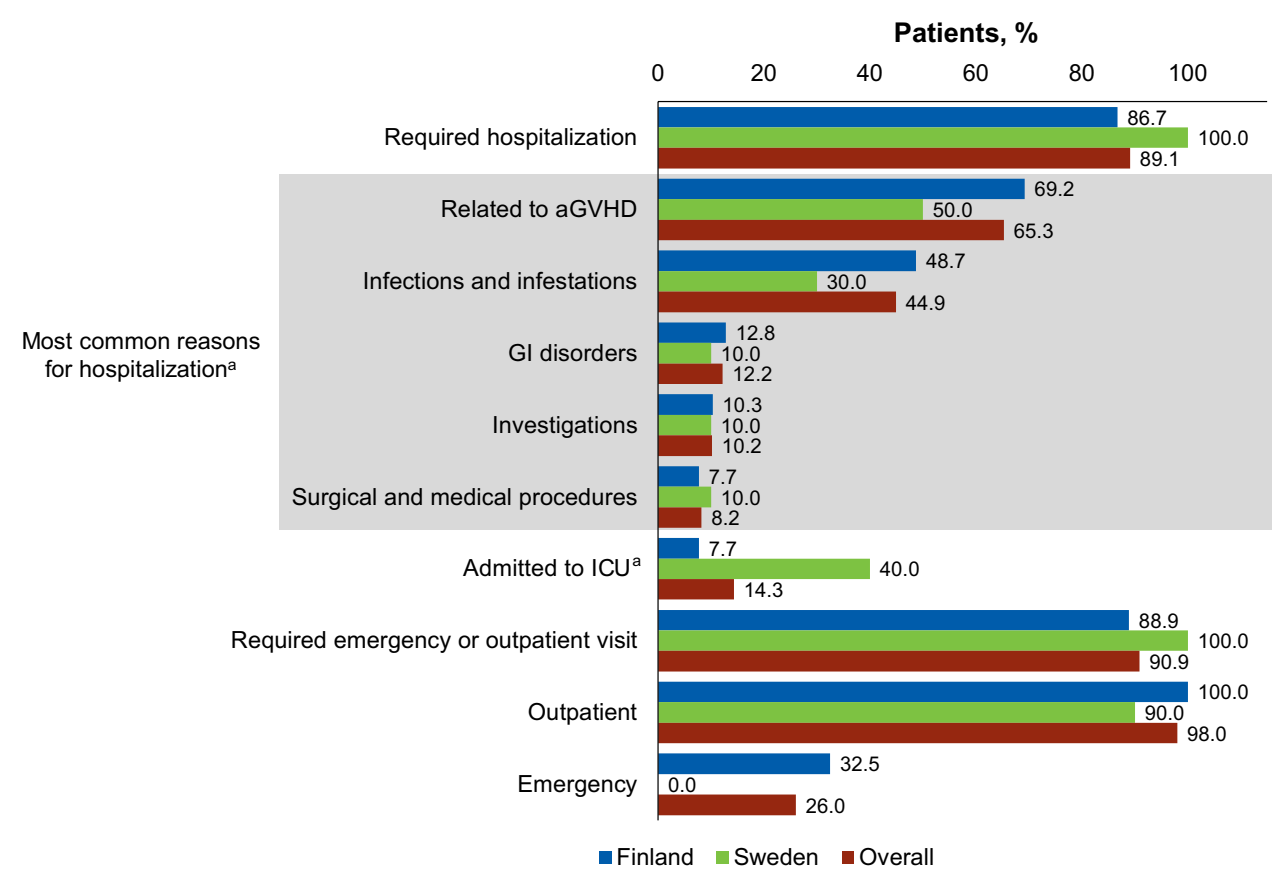


Table 2 Hospitalizations

\begin{tabular}{|c|c|c|c|}
\hline & Finland $(n=45)$ & Sweden $(n=10)$ & Total $(N=55)$ \\
\hline \multicolumn{4}{|l|}{ Number of hospitalizations per patient } \\
\hline Mean (SD) & $2.9(2.8)$ & $3.0(1.7)$ & $2.9(2.7)$ \\
\hline Median (range) & $2.0(0.0-10.0)$ & $2.5(1.0-6.0)$ & $2.0(0.0-10.0)$ \\
\hline \multicolumn{4}{|l|}{ Total days of hospitalization per patient ${ }^{\mathrm{a}}$} \\
\hline Mean (SD) & $31.8(30.8)$ & $83.0(79.8)$ & $41.3(47.5)$ \\
\hline Median (range) & $25.5(0.0-137.0)$ & $47.0(6.0-214.0)$ & $26.0(0.0-214.0)$ \\
\hline \multicolumn{4}{|l|}{ Days of hospitalization/100 patient-days ${ }^{\mathrm{a}}$} \\
\hline Mean (SD) & $15.4(30.1)$ & $29.2(36.2)$ & $17.9(31.4)$ \\
\hline Median (range) & $3.6(0.0-100.0)$ & $12.9(0.5-86.7)$ & $3.9(0.0-100.0)$ \\
\hline \multicolumn{4}{|l|}{ Days of ICU stay } \\
\hline Mean (SD) & $0.5(2.2)$ & $4.1(8.8)$ & $1.1(4.3)$ \\
\hline Median (range) & $0.0(0.0-14.0)$ & $0.0(0.0-28.0)$ & $0.0(0.0-28.0)$ \\
\hline \multicolumn{4}{|l|}{ Days of ICU stay/100 patient-days } \\
\hline Mean (SD) & $0.5(2.3)$ & $1.8(3.8)$ & $0.7(2.7)$ \\
\hline Median (range) & $0.0(0.0-13.5)$ & $0.0(0.0-12.3)$ & $0.0(0.0-13.5)$ \\
\hline Number of outpatient visits per patient-year, mean (SD) & $9.3(6.4)$ & $23.7(19.8)$ & $11.7(11.1)$ \\
\hline Number of emergency visits per patient-year, mean (SD) & $0.3(0.6)$ & 0 & $0.3(0.6)$ \\
\hline
\end{tabular}

$I C U$, intensive care unit. ${ }^{\mathrm{a} C a l c u l a t e d}$ based on number of patients requiring hospitalization (Finland, $n=44$; Sweden, $n=10$; total, $n=54$ )

\section{Subgroup analyses}

A subgroup analysis evaluating $\mathrm{H} \& \mathrm{OV}$ by number of treatment lines for aGVHD demonstrated similar rates of hospitalization between patients who received one treatment line $(n=22 / 24$ [91.7\%]) and those who needed at least 2 treatment lines $(n=27 / 31$ [87.1\%]). Patients who received at least 2 lines of therapy had a median hospitalization duration of 6.1 days per 100 patient-days, and those who received only one treatment line had 1.9 days ( $\geq 2$ lines vs 1 line, $P=0.03$; Table 3). Median number of hospitalization periods per patient and median number of days at ICU per 100 patient-days were the same between patients who received $\geq 2$ lines or 1 line of treatment. The proportion of the study population requiring outpatient or emergency department visits was $87.1 \%$ among patients with $\geq 2$ lines of prior treatment and $95.8 \%$ among those receiving only one prior line of treatment. The mean number of outpatient visits per person per year was similar for the 2 subgroups ( $\geq 2$ lines, $11.4 ; 1$ line, $12.0 ; P=0.16$ ). Mean number of emergency department visits per patient-year was two-fold higher for patients who received only 1 line of treatment compared with those receiving 2 or more lines ( $\geq 2$ lines, 0.2 visits/patient-year; 1 line, 0.4 visits/patient-year; $P=0.16$ ); however, it cannot be excluded that this may be due only to chance.

When $\mathrm{H} \& \mathrm{OV}$ was assessed by prophylactic regimen categories, the lowest rate of hospitalization was observed among patients who received tacrolimus plus mycophenolate, in vivo $\mathrm{T}$-cell depletion, and methotrexate $(71.4 \%$ vs
$100.0 \%$ for in vivo T-cell depletion plus methotrexate and cyclosporine, $100.0 \%$ for methotrexate plus cyclosporine, and $85.7 \%$ for other regimens). Patients who received tacrolimus plus mycophenolate, in vivo T-cell depletion, and methotrexate also spent considerably less (about half as many) days in the hospital on average ( 9.8 per 100 patientdays) compared with other treatment regimens. However, it cannot be ruled out that the observed differences may be due only to chance (Table 4).

\section{Mortality rates since aGVHD development}

At 6 months after aGVHD diagnosis, mortality rates in Finland and Sweden were 17.8\% $(n=8)$ and $10.0 \%(n=1)$, respectively. At 12 months, the mortality rates were $17.8 \%$ $(n=8)$ and $40.0 \%(n=4)$.

\section{Discussion}

The present study provides a detailed description of the clinical characteristics and aGVHD-related H\&OV of patients who developed aGVHD after allogeneic HSCT. These RWD were collected from 2 reference transplantation centers in Finland and one in Sweden. Owing to data availability, precise coverage of the Swedish population was unknown because exact estimates were not available; however, the study had a high coverage in the Finnish population, with 80 to $90 \%$ of nationwide eligible patients being included in this chart review study [23]. 
Table 3 Subgroup analysis of H\&OV by prior lines of treatment

\begin{tabular}{|c|c|c|c|c|}
\hline & 1 line $(n=24)$ & $\geq 2$ lines $(n=31)$ & $P$-value & Total $(N=55)$ \\
\hline Required hospitalization, n (\%) & $22(91.7)$ & $27(87.1)$ & & $49(89.1)$ \\
\hline Total number of hospitalizations & 55 & 104 & & 159 \\
\hline \multicolumn{5}{|l|}{ Number of hospitalizations per patient } \\
\hline Mean (SD) & $2.3(2.1)$ & $3.4(3.0)$ & 0.55 & $2.9(2.7)$ \\
\hline Median (range) & $2.0(0.0-10.0)$ & $2.0(0.0-10.0)$ & & $2.0(0.0-10.0)$ \\
\hline \multicolumn{5}{|l|}{ Duration of hospitalization per patient, days } \\
\hline Mean (SD) & $22.2(21.0)$ & $56.5(56.8)$ & & $41.3(47.5)$ \\
\hline Median (range) & $14.5(0.0-81.0)$ & $35.0(0.0-214.0)$ & & $26.0(0.0-214.0)$ \\
\hline \multicolumn{5}{|l|}{ Days of hospitalization/100 patient-days } \\
\hline Mean (SD) & $7.4(19.8)$ & $26.4(36.4)$ & 0.03 & $17.9(31.4)$ \\
\hline Median (range) & $1.9(0.0-98.4)$ & $6.1(0.0-100.0)$ & & $3.9(0.0-100.0)$ \\
\hline Required admission to ICU, $n(\%)^{\mathrm{a}}$ & $1(4.5)$ & $6(22.2)$ & & $7(14.3)$ \\
\hline \multicolumn{5}{|l|}{ Duration of ICU stay per patient, days } \\
\hline Mean (SD) & $0.6(2.9)$ & $1.6(5.2)$ & & $1.1(4.3)$ \\
\hline Median (range) & $0.0(0.0-14.0)$ & $0.0(0.0-28.0)$ & & $0.0(0.0-28.0)$ \\
\hline \multicolumn{5}{|l|}{ Days of ICU stay/100 patient-days } \\
\hline Mean (SD) & $0.3(1.7)$ & $1.0(3.2)$ & 0.50 & $0.7(2.7)$ \\
\hline Median (range) & $0.0(0.0-8.2)$ & $0.0(0.0-13.5)$ & & $0.0(0.0-13.5)$ \\
\hline Required outpatient or emergency department visit, $n(\%)$ & $23(95.8)$ & $27(87.1)$ & & $50(90.9)$ \\
\hline \multicolumn{5}{|l|}{ Type of visit, $n(\%)$} \\
\hline Outpatient & $23(100.0)$ & $26(96.3)$ & & $49(98.0)$ \\
\hline Emergency & $8(34.8)$ & $5(18.5)$ & & $13(26.0)$ \\
\hline Missing & 0 & $1(3.7)$ & & $1(2.0)$ \\
\hline Number of outpatient visits per patient-year, mean (SD) ${ }^{\mathrm{b}}$ & $12.0(7.9)$ & $11.4(13.2)$ & 0.16 & $11.7(11.1)$ \\
\hline Number of emergency department visits per patient-year, mean $(\mathrm{SD})^{\mathrm{b}}$ & $0.4(0.7)$ & $0.2(0.4)$ & 0.16 & $0.3(0.6)$ \\
\hline
\end{tabular}

$H \& O V$, hospital stays and outpatient visits; $I C U$, intensive care unit. ${ }^{a}$ Percentages calculated based on number of patients requiring hospitalization ( 1 line, $n=22 ; \geq 2$ lines, $n=27$; total, $n=49)$. ' Includes patients with nonmissing visit type information $(1$ line, $n=24 ; \geq 2$ lines, $n=30$; total, $n=54$ )

Although fewer than $30 \%$ of patients in the study presented with grade III or IV aGVHD, nearly $90 \%$ of patients required hospitalization. Overall, patients were hospitalized for a median of 26 days after a diagnosis of aGVHD and required more than 10 outpatient or emergency department visits per year. It should be noted that the hospitalization numbers in Gothenburg (Sweden) were higher than those reported in the 2 Finnish sites; one possible reason for this discrepancy is that it is standard at Gothenburg to call for multiple follow-up visits during the first few months after HSCT, with additional visits required following aGVHD diagnosis, which may result in hospital admissions. When stratified by treatment lines, patients who received at least 2 treatment lines had a longer hospital stay compared with those who received only one treatment line, although the rate of ICU admissions or length of treatment at ICU did not differ between these subgroups. With the exception of patients who received tacrolimus plus mycophenolate, in vivo T-cell depletion, and methotrexate, most prophylaxis regimens resulted in similar rates and duration of hospitalization or
ICU admissions. These findings are consistent with those of the few other available studies conducted in the USA. An analysis of a large data set of hospital discharges showed that patients diagnosed with aGVHD had a significantly longer length of stay during initial hospitalization for HSCT versus those without aGVHD (31 vs 24 days, respectively) and were more likely to require ICU admission (40.6\% vs $25.4 \%$ ) [13]. Another national analysis of inpatient discharge records similarly showed an increased length of hospital stay among patients who developed aGVHD after HSCT versus those who did not (42.0 vs 26.0 days, respectively), as well as increased in-hospital mortality rates (16.2\% vs 5.3\%) [14].

These study's findings show that, besides requiring considerable medical attention and arguably competing with other health conditions for limited healthcare resources, aGVHD is associated with a substantial financial burden for healthcare payers. In fact, based on the average cost of a day of hospitalization in Finland and Sweden, and on this study's results, the average cost per patient for aGVHD-associated hospitalizations would amount to $\sim \$ 25,000-\$ 40,000$ 
Table 4 Subgroup analysis of H\&OV by prophylactic regimen

\begin{tabular}{|c|c|c|c|c|c|}
\hline & $\begin{array}{l}\text { Tacrolimus, mycophenolate, } \\
\text { in vivo T-cell depletion, } \\
\text { methotrexate }(n=14)\end{array}$ & $\begin{array}{l}\text { In vivo T-cell depletion, } \\
\text { methotrexate, cyclosporine } \\
(n=20)\end{array}$ & $\begin{array}{l}\text { Methotrexate, } \\
\text { cyclosporine } \\
(n=7)\end{array}$ & Other $(n=14)$ & $P$-value \\
\hline Required hospitalization, $n(\%)$ & $10(71.4)$ & $20(100.0)$ & $7(100.0)$ & $12(85.7)$ & \\
\hline $\begin{array}{l}\text { Total number of hospitaliza- } \\
\text { tions }\end{array}$ & 46 & 64 & 15 & 34 & \\
\hline \multicolumn{6}{|l|}{$\begin{array}{l}\text { Number of hospitalizations per } \\
\text { patient }\end{array}$} \\
\hline Mean (SD) & $3.3(3.4)$ & $3.2(2.6)$ & $2.1(1.9)$ & $2.4(2.3)$ & 0.77 \\
\hline Median (range) & $3.0(0.0-10.0)$ & $2.0(1.0-10.0)$ & $1.0(1.0-6.0)$ & $2.0(0.0-9.0)$ & \\
\hline \multicolumn{6}{|l|}{$\begin{array}{l}\text { Duration of hospitalization per } \\
\text { patient, days }\end{array}$} \\
\hline Mean (SD) & $33.1(34.9)$ & $51.9(52.1)$ & $24.3(21.3)$ & $43.1(58.3)$ & \\
\hline Median (range) & $28.0(0.0-104.0)$ & $28.0(8.0-179.0)$ & $17.0(6.0-69.0)$ & $25.5(0.0-214.0)$ & \\
\hline \multicolumn{6}{|l|}{$\begin{array}{l}\text { Days of hospitalization/100 } \\
\text { patient-days }\end{array}$} \\
\hline Mean (SD) & $9.8(23.9)$ & $19.6(29.8)$ & $18.3(36.6)$ & $22.8(37.9)$ & 0.34 \\
\hline Median (range) & $3.8(0.0-91.9)$ & $6.4(1.2-97.9)$ & $1.7(0.5-100.0)$ & $3.1(0.0-98.4)$ & \\
\hline $\begin{array}{l}\text { Required admission to ICU, } \\
n(\%)^{\mathrm{a}}\end{array}$ & $1(10.0)$ & $4(20.0)$ & $1(14.3)$ & $1(8.3)$ & \\
\hline \multicolumn{6}{|l|}{$\begin{array}{l}\text { Duration of ICU stay per } \\
\text { patient, days }\end{array}$} \\
\hline Mean (SD) & $0.4(1.3)$ & $2.7(6.9)$ & $0.4(1.1)$ & $0.1(0.5)$ & \\
\hline Median (range) & $0.0(0.0-5.0)$ & $0.0(0.0-28.0)$ & $0.0(0.0-3.0)$ & $0.0(0.0-2.0)$ & \\
\hline \multicolumn{6}{|l|}{$\begin{array}{l}\text { Days of ICU stay/100 patient- } \\
\text { days) }\end{array}$} \\
\hline Mean (SD) & $1.0(3.6)$ & $1.2(3.3)$ & $0.1(0.3)$ & $0.1(0.4)$ & 0.65 \\
\hline Median (range) & $0.0(0.0-13.5)$ & $0.0(0.0-12.3)$ & $0.0(0.0-0.8)$ & $0.0(0.0-1.6)$ & \\
\hline
\end{tabular}

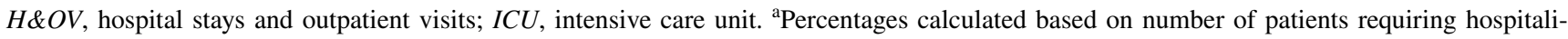
zation (tacrolimus, mycophenolate, in vivo T-cell depletion, methotrexate, $n=10$; in vivo T-cell depletion, methotrexate, cyclosporine, $n=20$; methotrexate, cyclosporine, $n=7$; other, $n=12$ )

USD and $\sim \$ 90,000$ USD, respectively; similarly, based on the average cost of an outpatient visit in Finland and Sweden, the cost per patient for aGVHD-related outpatient visits per year amounts to $\sim \$ 600-\$ 1700$ USD and $\sim \$ 4700$ USD, respectively (Online Resource 8 ). Although referring to a very different healthcare environment, these figures are overall comparable to those provided by a large US healthcare claims database study, which showed that the total healthcare costs incurred during a 1-year period following allogeneic HSCT were \$100,000 USD higher for patients who developed aGVHD; additionally, hospital length of stay was nearly 3 weeks longer than for those without aGVHD [15]. Therefore, the present study supports and reinforces the findings of the few recent (US-based) studies, providing novel figures specific to the burden of $\mathrm{H} \& \mathrm{OV}$ in Finland and Sweden.

Limitations of this study include those typical of a retrospective chart review, such as the potential for medical charts being incomplete or inaccurate. These potential issues may have affected the calculations of $\mathrm{H} \& \mathrm{OV}$ and hospitalization durations, as well as information on treatment and prophylaxis. Nonetheless, the chart abstraction was conducted by qualified investigators from the enrolled centers familiar with the local ways of recording medical information. Variables collected were standard and clinically meaningful within acute GVHD populations, and specific information on variable definition was collected when needed. The use of an electronic case report made possible the implementation of an algorithm that performed consistency checks across the data filled in for each patient, reducing the risk of reporting errors. Finally, additional checks and triangulation of the clinical information were performed during the analyses.

The differences in aGVHD organ staging and grading systems (i.e., MAGIC vs modified Glucksberg), which could have an impact on the interpretation of results, were addressed by grouping and restaging modified Glucksberg cases using MAGIC criteria, instead of doing the opposite mapping (which would be affected by considerably higher uncertainty due to stage and grade definitions in the 2 scales) or naively comparing patients graded in MAGIC 
with patients graded in Glucksberg, as explained in Online Resource 7. In addition, the study was also limited by the small sample size, limiting statistical comparisons, especially at the subgroup level and particularly for Sweden, where information was only available from one hospital. Finally, variability existed between the Finland and Sweden data sets in terms of patient selection, which may have also affected the calculations and findings of the study.

In conclusion, findings from this study show that moderate to severe aGVHD is associated with considerable $\mathrm{H} \& \mathrm{OV}$ in Finland and Sweden, particularly in patients who received multiple lines of therapy. Larger follow-up studies across multiple regions, including prospective analyses, should be conducted to assess the generalizability of these findings to the aGVHD patient population as a whole.

Supplementary Information The online version contains supplementary material available at https://doi.org/10.1007/s00520-022-06915-9.

Acknowledgements The authors thank Emilio Sanchez and Eleonora Zonta (IQVIA; Barcelona, Spain) for their contribution to programming and data analysis. Writing assistance was provided by Jane Kovalevich, PhD, and Vicky Kanta, PhD, employees of ICON (Blue Bell, $\mathrm{PA}$ ), and was funded by Incyte Corporation (Wilmington, DE).

Author contribution LS designed and performed research, analyzed and interpreted data, and wrote the manuscript. DT and MP analyzed and interpreted data and wrote the manuscript. MK, MN, and MI-R performed research, interpreted data, and wrote the manuscript. EV, $\mathrm{MR}$, and NL designed research, performed statistical analyses, and wrote the manuscript.

Funding This study was funded by Incyte Corporation.

Data availability Access to individual patient-level data is not available for this study. Information on Incyte's clinical trial data sharing policy and instructions for submitting clinical trial data requests are available at: https://www.incyte.com/Portals/0/Assets/Compl iance $\% 20$ and $\% 20$ Transparency/clinical-trial-data-sharing.pdf?ver= 2020-05-21-132838-960

Code availability Not applicable.

\section{Declarations}

Ethics approval The study was conducted in accordance with the protocol, good pharmacoepidemiology practices, and the ethical principles embodied by the Declaration of Helsinki and applicable privacy laws. Institutional review boards/independent ethics committees reviewed and approved the study protocol before any patients were enrolled.

Consent to participate This was a retrospective chart review study using de-identified patient data; therefore, no consent was required.

Consent for publication This was a retrospective chart review study using de-identified patient data; therefore, no consent was required.

Conflicts of interest Lorenzo Sabatelli, Daniel Thunström, and Minja Pfeiffer are employees and shareholders of Incyte Biosciences Interna- tional. Mikko Keränen has provided consulting services for Novartis, Amgen, Janssen-Cilag, Pfizer, and Incyte Corporation; has an ownership interest in Iovance Biotherapeutics (IOVA); and has received honoraria from Accord Healthcare, Astellas, AbbVie, Amgen, and Takeda. Elisabet Viayna, Montserrat Roset, and Nuria Lara are employees of IQVIA Real World Solutions. Malin Nicklasson and Maija Itälä-Remes report no conflicts of interest.

Disclosure of previous presentation Part of the results and methods of this manuscript were previously presented at Virtual ISPOR Europe 2020 (November 16-19, 2020).

Open Access This article is licensed under a Creative Commons Attribution 4.0 International License, which permits use, sharing, adaptation, distribution and reproduction in any medium or format, as long as you give appropriate credit to the original author(s) and the source, provide a link to the Creative Commons licence, and indicate if changes were made. The images or other third party material in this article are included in the article's Creative Commons licence, unless indicated otherwise in a credit line to the material. If material is not included in the article's Creative Commons licence and your intended use is not permitted by statutory regulation or exceeds the permitted use, you will need to obtain permission directly from the copyright holder. To view a copy of this licence, visit http://creativecommons.org/licenses/by/4.0/.

\section{References}

1. Zeiser R, Blazar BR (2017) Acute graft-versus-host disease - biologic process, prevention, and therapy. N Engl J Med 377:21672179. https://doi.org/10.1056/NEJMra1609337

2. Ferrara JL, Levine JE, Reddy P, Holler E (2009) Graft-versus-host disease. Lancet 373:1550-1561. https://doi.org/10.1016/S01406736(09)60237-3

3. Jagasia MH, Greinix HT, Arora M, Williams KM, Wolff D, Cowen EW, Palmer J, Weisdorf D, Treister NS, Cheng GS, Kerr H, Stratton P, Duarte RF, McDonald GB, Inamoto Y, Vigorito A, Arai S, Datiles MB, Jacobsohn D, Heller T, Kitko CL, Mitchell SA, Martin PJ, Shulman H, Wu RS, Cutler CS, Vogelsang GB, Lee SJ, Pavletic SZ, Flowers ME (2015) National Institutes of Health consensus development project on criteria for clinical trials in chronic graft-versus-host disease: I. The 2014 diagnosis and staging working group report. Biol Blood Marrow Transplant 21(3):389-401.e381. https://doi.org/10.1016/j.bbmt.2014.12.001

4. Schoemans HM, Lee SJ, Ferrara JL, Wolff D, Levine JE, Schultz KR, Shaw BE, Flowers ME, Ruutu T, Greinix H, Holler E, Basak G, Duarte RF, Pavletic SZ, EBMT Transplant Complications Working Party, EBMT-NIH-CIBMTR GvHD Task Force (2018) EBMT-NIH-CIBMTR Task Force position statement on standardized terminology \& guidance for graft-versus-host disease assessment. Bone Marrow Transplant 53:1401-1415. https://doi. org/10.1038/s41409-018-0204-7

5. Krejci M, Kamelander J, Pospisil Z, Mayer J (2012) Kinetics of bilirubin and liver enzymes is useful for predicting of liver graftversus-host disease. Neoplasma 59:264-268. https://doi.org/10. 4149/neo_2012_034

6. Greco R, Lorentino F, Nitti R, Lupo Stanghellini MT, Giglio F, Clerici D, Xue E, Lazzari L, Piemontese S, Mastaglio S, Assanelli A, Marktel S, Corti C, Bernardi M, Ciceri F, Peccatori J (2019) Interleukin-6 as biomarker for acute GvHD and survival after allogeneic transplant with post-transplant cyclophosphamide. Front Immunol 10:2319. https://doi.org/10.3389/fimmu.2019. 02319 
7. Jagasia M, Arora M, Flowers ME, Chao NJ, McCarthy PL, Cutler CS, Urbano-Ispizua A, Pavletic SZ, Haagenson MD, Zhang MJ, Antin JH, Bolwell BJ, Bredeson C, Cahn JY, Cairo M, Gale RP, Gupta V, Lee SJ, Litzow M, Weisdorf DJ, Horowitz MM, Hahn T (2012) Risk factors for acute GVHD and survival after hematopoietic cell transplantation. Blood 119:296-307. https://doi.org/ 10.1182/blood-2011-06-364265

8. Penack O, Marchetti M, Ruutu T, Aljurf M, Bacigalupo A, Bonifazi F, Ciceri F, Cornelissen J, Malladi R, Duarte RF, Giebel S, Greinix H, Holler E, Lawitschka A, Mielke S, Mohty M, Arat M, Nagler A, Passweg J, Schoemans H, Socie G, Solano C, Vrhovac R, Zeiser R, Kroger N, Basak GW (2020) Prophylaxis and management of graft versus host disease after stem-cell transplantation for haematological malignancies: updated consensus recommendations of the European Society for Blood and Marrow Transplantation. Lancet Haematol 7:e157-e167. https://doi.org/ 10.1016/S2352-3026(19)30256-X

9. Martin PJ, Rizzo JD, Wingard JR, Ballen K, Curtin PT, Cutler C, Litzow MR, Nieto Y, Savani BN, Schriber JR, Shaughnessy PJ, Wall DA, Carpenter PA (2012) First- and second-line systemic treatment of acute graft-versus-host disease: recommendations of the American Society of Blood and Marrow Transplantation. Biol Blood Marrow Transplant 18:1150-1163. https://doi.org/10. 1016/j.bbmt.2012.04.005

10. Major-Monfried H, Renteria AS, Pawarode A, Reddy P, Ayuk F, Holler E, Efebera YA, Hogan WJ, Wolfl M, Qayed M, Hexner EO, Wudhikarn K, Ordemann R, Young R, Shah J, Hartwell MJ, Chaudhry MS, Aziz M, Etra A, Yanik GA, Kroger N, Weber D, Chen YB, Nakamura R, Rosler W, Kitko CL, Harris AC, Pulsipher M, Reshef R, Kowalyk S, Morales G, Torres I, Ozbek U, Ferrara JLM, Levine JE (2018) MAGIC biomarkers predict long-term outcomes for steroid-resistant acute GVHD. Blood 131:2846-2855. https://doi.org/10.1182/blood-2018-01-822957

11. Stauber MN, Aberer F, Oulhaj A, Mader JK, Zebisch A, Pieber TR, Neumeister P, Greinix HT, Sill H, Sourij H, Wolfler A (2017) Early hyperglycemia after initiation of glucocorticoid therapy predicts adverse outcome in patients with acute graft-versus-host disease. Biol Blood Marrow Transplant 23:1186-1192. https:// doi.org/10.1016/j.bbmt.2017.03.010

12. Dignan FL, Potter MN, Ethell ME, Taylor M, Lewis L, Brennan J, McNamara L, Evans SO, Riley U, Davies FE, Dearden CE, Morgan GJ, Shaw BE (2013) High readmission rates are associated with a significant economic burden and poor outcome in patients with grade III/IV acute GvHD. Clin Transplant 27:E56-63. https:// doi.org/10.1111/ctr.12065

13. Yu J, Judy JT, Parasuraman S, Sinha M, Weisdorf D (2020) Inpatient healthcare resource utilization, costs, and mortality in adult patients with acute graft-versus-host disease, including steroidrefractory or high-risk disease, following allogeneic hematopoietic cell transplantation. Biol Blood Marrow Transplant 26:600 605. https://doi.org/10.1016/j.bbmt.2019.10.028

14. Yu J, Parasuraman S, Shah A, Weisdorf D (2019) Mortality, length of stay and costs associated with acute graft-versus-host disease during hospitalization for allogeneic hematopoietic stem cell transplantation. Curr Med Res Opin 35:983-988. https://doi.org/ 10.1080/03007995.2018.1551193
15. Grubb WW, Huse S, Alam N, Dychter S, Wingard JR, Majhail NS, Berger A (2016) Economic burden of acute graft-versus-host disease (GvHD) following allogeneic hematopoietic cell transplant (HCT) for hematologic malignancies. Blood 128:1187. https:// doi.org/10.1182/blood.V128.22.1187.1187

16. Svahn BM, Alvin O, Ringdén O, Gardulf A, Remberger M (2006) Costs of allogeneic hematopoietic stem cell transplantation. Transplantation 82:147-153. https://doi.org/10.1097/01.tp. 0000226171.43943.d3

17. Svahn BM, Remberger M, Alvin O, Karlsson H, Ringdén O (2012) Increased costs after allogeneic haematopoietic SCT are associated with major complications and re-transplantation. Bone Marrow Transplant 47:706-715. https://doi.org/10.1038/bmt. 2011.162

18. Harris AC, Young R, Devine S, Hogan WJ, Ayuk F, Bunworasate U, Chanswangphuwana C, Efebera YA, Holler E, Litzow M, Ordemann R, Qayed M, Renteria AS, Reshef R, Wolfl M, Chen YB, Goldstein S, Jagasia M, Locatelli F, Mielke S, Porter D, Schechter T, Shekhovtsova Z, Ferrara JL, Levine JE (2016) International, multicenter standardization of acute graft-versus-host disease clinical data collection: a report from the Mount Sinai Acute GVHD International Consortium. Biol Blood Marrow Transplant 22:4-10. https://doi.org/10.1016/j.bbmt.2015.09.001

19. Przepiorka D, Weisdorf D, Martin P, Klingemann HG, Beatty P, Hows J, Thomas ED (1995) 1994 Consensus conference on acute GVHD grading. Bone Marrow Transplant 15:825-828

20. Rowlings PA, Przepiorka D, Klein JP, Gale RP, Passweg JR, Henslee-Downey PJ, Cahn JY, Calderwood S, Gratwohl A, Socie G, Abecasis MM, Sobocinski KA, Zhang MJ, Horowitz MM (1997) IBMTR Severity Index for grading acute graft-versus-host disease: retrospective comparison with Glucksberg grade. Br J Haematol 97:855-864. https://doi.org/10.1046/j.1365-2141.1997. 1112925.x

21. Armand P, Kim HT, Logan BR, Wang Z, Alyea EP, Kalaycio ME, Maziarz RT, Antin JH, Soiffer RJ, Weisdorf DJ, Rizzo JD, Horowitz MM, Saber W (2014) Validation and refinement of the Disease Risk Index for allogeneic stem cell transplantation. Blood 123:3664-3671. https://doi.org/10.1182/ blood-2014-01-552984

22. Armand P, Gibson CJ, Cutler C, Ho VT, Koreth J, Alyea EP, Ritz J, Sorror ML, Lee SJ, Deeg HJ, Storer BE, Appelbaum FR, Antin JH, Soiffer RJ, Kim HT (2012) A disease risk index for patients undergoing allogeneic stem cell transplantation. Blood 120:905-913. https://doi.org/10.1182/blood-2012-03-418202

23. European Society for Blood and Marrow Transplantation. Adult acute GvHD cases in Europe between 2014-2018 [unpublished data available from EBMT upon request, specific fees may apply]; 2019.

Publisher's note Springer Nature remains neutral with regard to jurisdictional claims in published maps and institutional affiliations. 